\title{
Dissimulation and simulation as forms of religious reflexivity
}

\author{
Michael Houseman \\ Ecole Pratique des Hautes Etudes (EPHE), Paris
}

(Social Anthropology 10 (1): 77-89, 2002)

\begin{abstract}
This paper discusses conventional illusory enactments, largely recognised as such by those who undertake them, drawn from two Central African male initiation rites : the novices' dramatic execution on the one hand, and the purportedly painless sacrifice of the ritual's emblematic animal on the other. In doing so, it attempts to elucidate two related forms of religious reflexivity: ritual "dissimulation", centred around the manipulation of persons, and ritual "simulation", founded upon the manipulation of non-persons (animals, objects, spells, images, and so forth). The actors' commitment to such performances as necessary and appropriate ones is related, in the first case, to the interdependent relationship that is set up between the perceptions different categories of participants have of the event they are jointly involved in, and in the second case, to the way the mediating qualities of non-persons serve to embed the participants' actions within auto-referential circuits in which relations of causality and representation converge.
\end{abstract}

This paper deals with ritual simulation within the context of initiation rites. This inevitably involves trying to show that ritual secrecy is more than a matter of some people pulling the wool over other peoples' eyes. Although I will address this issue, my main concern is not with ritual secrecy as such, but with the emergent properties of ritual simulation generally. I am particularly interested in exploring how the recourse to conventional illusory enactments, largely recognised as such by those who undertake them, may provide the basis for the participants' commitment to the ritual actions they are involved in.

Two examples will be discussed. Both are drawn from Central African initiation rites and both have to do with killing. The first, found in many male initiations, concerns the initiatory execution of the novices: while being observed from afar by the women and children, the initiators stage an elaborate performance in which the novices are shown to be put to death. The second example, less wide-spread, concerns the divinatory sacrifice, undertaken by the initiators and in their presence alone, of the initiation rite's emblematic animal. In the present case, a goat is either slowly cut up or dismembered by hand when still alive without making a sound; it's silence indicates that the initiation has been successfully accomplished. One thing these killings have in common is that they both entail a degree of acknowledgement or consent on the part of those involved. This, however, brings out an important difference between them. In the first case, the novices' death is, of course, a sham, whereas the consent manifested by both the novices' and the women's active participation is real. In the second case, the reverse holds true: the goat is truly killed but its silent consent, and more significantly, the initiators' endorsement of this consent, is a ruse brought about by special herbs previously added to the animal's food.

The question I wish to explore is the following: in what ways does the overtly recognised make-believe quality of these episodes structure and sustain the participants' conviction that the ritual realities these practices portray are effective? In other words, how do such performances give rise to new, authoritative, eminently transmittable meanings, held by the participants to be inherent in the simulated actions themselves?

I will try to show that the illusory character of performances such as these does not so much mask their counterfeit nature as it provides the reflexive conditions that underlie the participants' commitment to them. Paradoxically enough, the apparent spuriousness of such 
events upholds rather than belies their significance. From an exterior, detached standpoint (such as that of the anthropologist), those who undertake these actions are confronted with a conceptual dilemma: are the novices' death and the goat's silence, at once supposedly efficacious yet apparently factitious, "true" or "false"? However, and this is a crucial point, such persons are not neutral observers but active participants. It is indeed the very form of their involvement in such episodes - the perceptual constraints and conceptual assumptions this involvement imposes upon them - that allows them to appreciate these events as the meaningful mysteries that they are. Specifically, by being made aware of the artificial character of the nonetheless mandatory actions they undertake, participants are induced to envisage their actions and themselves from a point of view other than their own, and it is the systemic interplay between their own and this other, hypothetical perspective that provides the basis for presumed meaningfulness of the events concerned. In the novices' execution, an example of what I will call ritual "dissimulation", this further point of view is implied, for the novices and for the uninitiated women, by the interaction that takes place between these two parties; in the goat's silent demise, an instance of what I will call ritual "simulation", it is implied, for the initiators, by the connection this sacrifice establishes between their behaviour as initiators and their own initiation.

Following an analysis of the novices' execution and of the goat's divinatory sacrifice, the relationship between the two forms of ritual reflexivity involved in these episodes "dissimulation" on the one hand, "simulation" on the other - will be briefly examined. ${ }^{1}$

\section{The novices' execution: a case of ritual dissimulation}

The labi initiation of the Gbaya Kara of the Central African Republic (Vidal 1976) is a three-year long ritual that, for a given village, takes place every seven to eight years. It is undergone by all males between the ages of twelve and seventeen, sexual relations before initiation being strictly prohibited. The novices (also called labi) are removed from their homes to a first camp located in the bush at least a kilometre away from the village. After an initial period during which they learn to dance and to speak the special initiatory language (labi), the novices spend almost two years in seclusion. While their hunting activities provide most of the village's meat and fish, the novices are forbidden from seeing women or from being seen by them. The young men are then moved to a second camp, approximately 200 metres from the village, where they spend an additional year. During this latter period the novices work in the village fields and have progressively more contacts with the uninitiated. Women increasingly participate not only as spectators during the dance exhibitions that take place at the second camp, but also, following the initiators' instructions, as full-fledged protagonists. In one episode, for example, women who are not the novices' mothers pour seemingly endless amounts of water on the young men who, covered with leaves, lie prone and silent on the ground in the cold of dawn. During the ritual's final event, "washing the labi", the novices, after having secretly killed a goat in a nearby stream, enter the village in procession; they are violently seized by the women who install them in front of their respective natal houses where they receive gifts from the crowd. The novices' first obligation following their initiation is to build houses of their own.

The episode of the novices" "death", called "killing the labi" takes place towards the beginning of the ritual, right before they are brought to the first camp. Here is an abbreviated account:

\footnotetext{
${ }^{1}$ It should clear that the "reflexivity" involved here - the recognition of another's perception of oneself - is very different from the contemplative "reflection" upon cultural values associated with liminality (Turner 1967) or the "public reflexivity" or collective stocktaking afforded by social dramas (Turner 1989).
} 
The day before the novices are to be put to death, there is a large party during which adulterous promiscuity, particularly on the part of the women, is tolerated. The novices retire early, not to their mother's hut as they have done until now, but to an unused house belonging to the ritual's organiser. They spend a sleepless night there in apprehension (they are told that the next day they will die) while, outside, the festivities continue. At dawn, they dress up in sumptuous clothes offered by members of the audience, notably their female kin, and begin to dance. The men strike them lightly on the back with small sticks, an action which enrages the women who begin insulting the men, calling out mournfully for their sons. The novices interrupt their dance and eat a last meal served by their mothers. When they resume dancing their mothers and sisters cry abundantly.

Around noon, the women and children are chased from the village. The organiser of the initiation gives the novices advice about their coming "death": he tells them that when the "killer" appears, they should behave like corpses, that they must not be afraid and, above all, that they must not struggle, for if they do they run the risk of really dying. The women return and the novices begin dancing again, singing, along with the women: "Oh father, are you tricking me?". All of a sudden, the men throw ashes in the boys' eyes and bundle them off into the bush, running as fast as possible and brutally dragging the novices along. The women scream and wail and try to follow the men.

After about a kilometre of running, the men and the novices arrive at a stream which has been dammed up to form a large pool. The novices are undressed and thrown into the water. They are dragged over to the dam where their initiatory godfathers hold them between their legs such that they are lying on their backs half in the water. The boys stop struggling and appear to be unconscious, their heads thrown back with their mouths half in the water and their eyes rolled up. They are covered with skins and branches so that only their heads are visible from time to time. Some men stand in the pool along its sides and, while singing, begin to beat the water with leafy branches, causing waves which sometimes cover the novices' heads. Most of the men are gathered around the pool and in this way more or less hide the scene from the women stationed several dozen metres away.

After a short time, the "killer" appears from behind a hidden blind in the pool and begins dancing towards the novices. He wears a wide-brimmed hat that hides his face; only his arms, holding a bunch of spears, is visible. As soon as he appears, the women begin to scream anew. The killer approaches the novices and with a small spear-point touches each of their bellies that protrudes out of the water. The hides and branches covering the novices are taken away, and the killer returns, this time holding a long spear aloft. He plunges this spear into the water such that it appears to enter the body of the youngest boy. He moves on to the next boy, and the next, leaving his spear planted in the body of the final novice (the spear is held under water by the novice's god-father). The men move aside so that the women can see clearly. The women begin to scream even louder, insulting the killer and moving to attack him. He responds with a condescending smirk and removes his spear from the body of the last boy. The men then chase the protesting women away.

The singing stops and, in silence, the novices are dragged from the water. Wrapped in hides and leaves and heaved onto the men's shoulders, they are carried off across the savannah towards the initiation camp. Part way there, once out of the women's sight, these packages are violently thrown to the ground and the exhausted 
and shocked novices emerge to be led towards the camp where they will spend two years in seclusion.

Many aspects of this episode deserve commentary. One is the on-going back-and-forth movement of the novices between the women and the men : the novices are transferred from their mother's hut to a house belonging to the ritual's organiser; the next day, they dance in prestigious clothes provided mainly by their female kin and are then playfully struck with small sticks by the men; they are then given a last meal by their mothers, and following that, are let in on an initial secret by their initiators. The ambivalent nature of the novices' position is clearly attested by the song they sing right before their execution: "Oh father, are you tricking me?". Another striking aspect is the peculiar and often ironical mixing of different emotional expressions that accompanies these acts: the mothers' sexual provocativeness on the dance grounds outside, coupled with the novices' fear and anxiety inside the organiser's house; the mothers' pride at the novices dancing and the initiators' mocking attitude towards their inept movements; and finally, the ambiguous way the novices are treated, both by the men, who are alternatively protective and abusive of them, and by the women, who wail mournfully but neglect to warn the boys that ashes are about to be thrown in their eyes and that they will be dragged off to the bush. These and other features are to be appreciated within the framework of the complex relationship of secrecy acted out in the course of this episode.

The illusory character of the novices' coming execution is revealed to them by the organiser of the ritual. The women are chased away beforehand, such that both the women and the novices are made aware of the fact that a secret exists between the initiators and the novices from which the women are excluded. The novices (and the initiators) are presumed to know something that the women do not. However, the revelation made to the novices is more intimidating than it is informative. They are not told exactly what will happen to them, but only that they must act as dead and that if they struggle or resist, then they may indeed die. Under threat, they blindly submit to the initiators' brutal and disorientating handling. Although the novices are placed at the centre of the killing scene, the very nature of their participation makes it impossible for them to see or properly understand what is going on: they are blinded by ashes, dragged quickly through the bush, held tight by their god-fathers, covered with branches, eyes rolled back with their heads half in the water, etc. The event of their "death", while painfully real, thus remains largely inaccessible to them. Herein, then, lies a further, less obvious deception: contrary to what the women may be led to imagine, the novices have little grasp of the nature of the activities they are nonetheless directly engaged in.

As for the uninitiated, and specifically the novices' mothers, they are thrust not into the centre of the ritual arena, but onto its periphery. They are thus afforded only a partial and distant view of the novices' execution, such that they too are incapable of forming a clear idea of exactly what is happening to the novices. Moreover, this episode is distressing for them as well, not only because it is dangerous for their sons - every once in a while one of the boys drowns -, but also because of the very real separation it invariably brings about: their relationship with the novices, whom they will not see for two years, will be forever changed. At the same time, however, the women want their sons to be initiated and are anxious not to be responsible for anything going wrong. From this point of view, they are compelled to act as the initiators' accomplices. For the novices, the women's angry wailing, which they cannot help but hear, attests to the fact that the women suppose that the "death" of the novices is real. However, for a good number of these women who, unlike the novices, have been through this scene a number of times, they more than suspect that the killing is a pretence, although they are pointedly not given sufficient means to be sure. In this way, a still further deception is 
involved: just as the uninitiated are led to falsely presume that the novices know what is really going on, the novices are led to falsely presume that the uninitiated decidedly do not.

The positions occupied by the novices and the uninitiated with respect to the initiators and to each other are thus symmetrically inverted. The novices are engaged in an overt but forced collusion with the initiators against the uninitiated; at the same time, they are themselves the object of a painful but covert duplicity on the part of the initiators (and the uninitiated). The uninitiated, on the other hand, are the object of a painful but overt duplicity on the part of the initiators (and the novices) and, at the same time, are engaged in a forced but covert collusion with the initiators against the novices.

In this episode, the novices and the uninitiated are involved in acting out what we may call an overtly "exhibited" secret - the young boys' violent execution - from opposite sides of the ritual stage. However, the veritable character of this performance - as being either clearly "true" or clearly "false" - is revealed to neither party. This episode, as a source of pain and anxiety for the novices and for the uninitiated is, for them, undeniably real. Nevertheless, their participation in this event is such that its essential nature remains obscure. In short, for both categories of participants (albeit in different ways), the novices' death is rendered at once experientially anchored and conceptually uncertain. While both parties are to some degree made aware of the factitious quality of this enactment, its mysterious, arresting yet indecipherable character remains intact.

The actual extent of the various participants' substantive knowledge, like the amount of coercion or the degree of expressive intensity their behaviour entails, surely varies from one performance to the next, and within any given performance, from one individual to the next. Some novices, for example, may have been previously informed (by elder brothers?) of the nature of their coming execution; some of the women may be truly worried about their sons being killed while others are not. Such considerations, however, are of minor importance, for whatever ideas the novices or the uninitiated may entertain regarding the former's execution, both remain committed to the actuality and to the effectiveness of this event, that is, to the idea that the novices ostensible "death" is the necessary and appropriate means for attaining adult Gbaya Kara manhood. This commitment, I suggest, is grounded in the two additional acts of what we may call "unavowed" secrecy which the novices and their mothers are also involved in.

On the one hand, the initiators' and the novices' actions, notably the chasing away of the women following the novices' final maternal meal, induce the uninitiated to presume that the novices are knowingly party to the operations they are engaged in, whereas in fact, the boys, impelled by the initiators as are the uninitiated themselves, remain largely ignorant of what befalls them. On the other hand, the initiators' and the uninitiateds' actions, in particular the women's loud protestations during the novices' execution, lead the latter to assume that the uninitiated do not imagine that their death is feigned, whereas in fact, the women, in spite of being openly kept in the dark by the initiators, know more than they let on. These two further dissimulations integrate in such a way as to sustain, for these two categories of participants, the presumed meaningfulness of the mysterious performance they act out. It is because the novices blindly obey the initiators in simulating their execution, thereby confirming, for the women, their supposed complicity with their initiators, that the women are able to freely assume their crying and protesting role, thereby belying what "inside" knowledge they may have. Reciprocally, it is because the women do so that, for the novices, their execution, whose precise nature remains for them obscure, may be overtly constituted, after the fact, as a significant (but largely illusory) secret never to be revealed to the uninitiated.

The very nature of the novices' and the uninitiated's involvement in the former's execution makes it difficult for either to be certain about what exactly this "death" entails. 
However, what is certain for both categories of participants, beyond the painful and anxietyprovoking character of the interactions they are engaged in, is the perception of each others' behaviour in relation to their own. It is this social perception, I suggest, rather than any definite conceptualisation of the episode in question (is it "real" or "simulated"?, what is its "true" meaning?, etc), that provides the grounds for their personal commitment to the genuine effectiveness of this event (cf. Houseman 2000). The women's wailing leads the novices to infer that their mothers may well imagine their being truly killed; this justifies the novices' (and the initiators') attitude of aggressive secrecy towards them, which induces the women to infer that the novices cannot imagine that the uninitiated may well be aware that their death is a sham; this, in turn, justifies the women's dramatic wailing on their behalf. Each party's actions are thus validated by the other's supposedly misguided perceptions as these may be inferred from the latter's overt behaviour. The novices and the uninitiated find themselves caught up in a complex relational dynamic in which the import of the novices' execution derives less from what substantive knowledge they may or may not have of it, than from the formal interplay of each other's unavowed deceits. While neither party is capable of forming a clear idea of what the novices' death precisely consists of, both are implicated in deceiving the other regarding the actual nature of this event. This systemic corroboration, in which feigned ignorance and partial understanding both play an essential role, endows this episode, for both parties, with a measure of partially inscrutable yet authentic meaning, as something whose nature, while to some extent uncertain, must not be revealed. In this way, the novices' execution imposes itself upon the novices and the uninitiated alike as an incontestably significant experience, implying some higher order of intelligibility, partially grasped by the novices and the uninitiated, but fully understood by the initiated alone and accessible solely through an accomplishment of the ritual acts themselves.

To conclude, it is worth noting that this interactive pattern implies that both the novices and the uninitiated women entertain several different points of view simultaneously (what Bateson [1979], referring to a method of analysis, has called "double description"). It also requires that for both categories of participants, in spite of the urgency arising from the painful quality of this episode, the conceptual indeterminacy regarding the genuine or factitious nature of the novices' execution remains to some degree unresolved. Both parties are placed in an eminently reflexive or questioning state of mind regarding not only the nature of the novices' "death" but also the status of their own actions in it. Indeed, the "unavowed" dissimulations that are a central component of the interactive scheme they are engaged in are largely predicated upon a lack of coincidence between the participants' private attitudes and their overt behaviour. This does not mean that the novices and the women are not personally involved in what they are doing, but rather that the emotional and informational underpinnings of this involvement may vary from one individual to the next. It is above all the participants' outward actions and their awareness of others' actions in relation to their own, rather than their inner feelings or understandings, that provide the grounds for the systemic coordination that underlies their commitment to the meaningfulness of the actions they undertake.

Finally, it should be clear that the interactive pattern described above relies upon the partially dissimulated character of the novices' execution. Paradoxically enough, it also relies upon the fact that the participants are made aware, to some degree, that this performance is not what it purports to be, that is, a killing in the ordinary sense of the term. As a result, for both the novices and the women, the reality of this event remains a highly ambiguous one. However, this uncertainty, integrated as it is within a complex interactive process, far from undermining the significance of this episode, provides the condition for the production of shared meaning: the conviction that "killing the labi" is the unavoidable and fitting procedure 
for attaining Gbaya-kara manhood. Indeed, the only participants for whom absolute certainty may be said to exist, and who are therefore largely excluded from this shared meaning, are the very young children, for whom, presumably, the novices' death is simply, unquestionably real. They are the only ones for whom it may be said that this episode represents a case of straight out deception, one to which all of the other participants contribute -- initiators, novices and women alike.

There remains, of course, the matter of the initiators themselves: what is their position in all this?

\section{The sacrifice of the Oyomo goat: a case of ritual simulation}

In principle, the initiators are party to all of the secrets that set the novices and the uninitiated against each other: they are well aware of how little the novices actually know and correctly surmise that the women already know more than they should. In this sense, the initiators, fully cognisant of the simulation involved in the novices' death, cannot be caught up in its performance in the same way. How, then, can we account for their commitment to what is, for them, an obvious deceit?

One might argue, in keeping with a pragmatic version of what G. Herdt has called the "ontological dimension" of secrecy - the idea that "to conceal things [...] is also to "create"" (1990:365) -, that the demonstrable success of the sham is in itself sufficient cause. This feigned execution may be shown to bring about the relational and other changes it purports to effect: when the uninitiated next see the novices they are profoundly transformed, both physically and in the way they act. The new initiates adopt an attitude of secrecy towards the women and other uninitiated who profess their ignorance. The initiators may therefore legitimately conclude that there is more to their simulation than what it might superficially appear to them to be. I suspect that that is not the whole story. To try to show this, I will consider a somewhat extreme case of a simulation performed by initiators in which no secrecy whatsoever is involved, taken this time from the so rite among the Beti of Southern Cameroon (cf. Houseman 1984, 1993; Laburthe-Tolra 1985).

The $s o$ initiation ritual, outlawed since the beginning of the $20^{\text {th }}$ century, was a one and a half year-long event whereby young men acquired the right to undertake those activities that define male adulthood in Beti society (marriage, speech in public meetings, residential autonomy, etc). During an initial phase of several months taking place in or around the village, the novices' innate aptitude for manhood was ostentatiously displayed by means of showy parades, public scarification, military exercises, etc. At the end of this time, the novices accompanied their initiators on a several-week long hunting trip in the forest. During this trip, unbeknownst to the women and other uninitiated persons, the novices were submitted to a variety of hardships, most of which entailed an ironic and painful relationship with objects or activities normally associated with adult men. Many had to do with hunting. For example, a novice was told to catch a hedge-hog hiding in a ditch overlaid with branches; when the boy did so, his hand wass bitten by the initiator hiding in the ditch. The novices, invited to participate in a wild pig hunt, were made to run on all fours, chased by their initiators, for hours; led to a hunter's lean-to to "rest", they were forced to squeeze themselves into a low hut made of thorny vines and built over a bog filled with excrement. They were made to "wash" with pepper-filled and dirty water, to pick "kola nuts" by climbing to the top of a tree swarming with poisonous ants, to "forge" by getting their hands crushed, etc. During these hazing episodes, the novices' attributes of adult manhood, so amply demonstrated during the first stage, were systematically and violently denied. Returning from this trip, the novices took up residence in a screened-off initiation camp on the outskirts of the village. There, within 
hearing of the uninitiated but out of their sight, they were made to undergo the various spectacular ordeals that comprise the ritual's climactic moment (the "death of the so"): eating a disgusting mixture (called "so fat"), rolling in the mud and destroying the women's gardens while imitating wild pigs, having stinging ants thrown upon them and going through a long tunnel with bunches of nettles hanging on it's walls. Following this, the novices remained in seclusion for a period of one year, subject to progressively less stringent prohibitions. They emerged at the ritual's final ceremony during which the feminine apparel the novices wore during the last phase of their seclusion was stripped away by their classificatory "wives" (women married into their lineage groups), whose clothing was torn off as well.

The episode that concerns us here is the following:

Following the novices' consumption of the mysterious "so fat" and their ensuing "death" (the "death of the so"), and prior to the novices' seclusion, the initiators sacrificed a castrated goat that had been previously staked out in the forest to be fattened as much as possible. This animal, designated by the name Oyomo, was slaughtered in a highly peculiar fashion. It was carved up, or according to other accounts, torn limb from limb, while still alive. If the goat cried out, the ritual, and specifically the novices "death" was considered invalid and had to be started over. A portion of the goat's fat was placed within the special goat-skin bag of the principal officiant (the "so bag"). It was mixed in with equivalent bits of fat taken from the sacrificial animals of previous initiations. This fat constituted the essential component of the "so fat" which will be consumed in subsequent initiations by the novices prior to their "death".

Now this episode takes place in the sole presence of the initiators. They are fully aware that the seemingly miraculous behaviour of the Oyomo goat in fact results from their own artifices: it is they themselves who drug the animal by adding certain herbs to its food. What then underlies the initiators commitment to such an apparently unnecessary simulation?

Here again, we may argue that to the extent that (1) the fat of this animal is held to be instrumental in the relational changes mediated by the ritual's performance (fat is closely related to sperm and more generally to masculinity among the Beti), and (2) that these changes are indeed seen to take effect, this would incite the initiators to appreciate their artifice as more than the spurious trick it appears to be. There are, I think, at least two directions in which we can try to go further.

The first relates to P. Boyer's (1990) observation, in connection with divinatory practices, that people seem to "automatically" attribute a higher degree of plausibility to discourse and action in which relations of causality and representation are systematically conflated. Thus the soothsayer's words and gestures are presumed to be true (more exactly, they are presumed to be truer than ordinary speech and behaviour), because they are presented as at once a description of the state of some (invisible) world or entity, and a consequence of this world's or entity's intervention. Initiation rituals are, of course, an exact complement of this: they constitute at once a representation or description of the novices' (dissimulated) transformation and, as the sole source of initiators, this transformation's necessary condition or cause. This applies to the killing of the Oyomo goat and to the novices' execution alike.

Thus, it is relevant to note that while the goat's sacrifice is instrumental in the metamorphosis the novices are held to undergo, at the same time, its own transformation is analogous to that undergone by the novices themselves. As I have shown elsewhere (Houseman 1984), the novices' passage through the ritual corresponds to a two-fold operation. First, through a series of severe, paradoxical ordeals during their hunting trip with 
their initiators, the novices' original identity as virtual men, deriving from their being born male and confirmed during the rite's initial phase, is ironically and violently denied. Next, beginning with the liminal, virile entities they have become, the novices' new ritual identity as future initiates is built up, notably through their ingestion of "so fat" and their participation in the mysterious "death of the $s o$ ". The Oyomo goat undergoes a similar process. Following a confirmation of its initial identity as a domestic animal by its willingness to accept (drugged) food from the initiators, the goat's animal nature, ironically enough, is violently negated by means of a painful slaughter in which it does not cry out. Oyomo is thus reduced to its overabundant fat, substance which then provides the basis for the construction of a new, ritual identity, that of the "so fat" kept within the principal officiant's ceremonial "so bag". In this way, whereas the novices, entering the rite as male children, are made into adult men destined to initiate others, the Oyomo goat, beginning as a fattened domestic animal, is transformed into a goat-skin bag containing "so fat" to be consumed by the novices of subsequent initiations. The analogies that can be drawn between the goat's painful death and the novices' hardships, and between the goat's silence and the novices ability to keep a secret are, in this respect, hardly accidental.

An additional and perhaps more fundamental consideration concerns the recursive circuit the goat's silent death establishes between successive performances of the ritual. Admittedly, this is but a further elaboration of the we-must-be-doing-something-right line of reasoning outlined above, applied to the relationship between the novices' initiation and those in which their initiators were themselves initiated. In so far as the novices' initiation is ascribable to their ingestion of "so fat", whose essential ingredient is the fat taken from the sacrificial goats of preceding initiations, the goat's silence consecrates the meaningfulness of the goats' silences on these preceding occasions; this consecration, in turn, authenticates the presumed meaningfulness of the goat's silence in the case at hand. This, of course, is but a special instance of the auto-referential pattern underlying initiation generally. As J. La Fontaine (1977) has observed, given the secret, unspeakable nature of initiatory events, the main ostensible proof of the transformation these events are supposed to bring about is the novices subsequent ability to initiate others. Thus, given that the initiators' ability to act as the agents of the novices' initiation derives from their own initiations, their intervention constitutes a corroboration of their own transformation, brought about by a previous performance of the same ritual. It follows that, to the degree that the procedures undertaken by them in the novices' initiation - the killing of the Oyomo goat, the novices' execution - are recognisable as similar to those undertaken for them in their own initiations (elder initiators obviously play an important role here), these operations may be presumed to be highly significant, regardless of their partial inscrutability.

The initiators direct the novices and the uninitiated in undertaking spectacular, "secret" performances such as the novices' execution. The purposeful infliction of suffering these performances entail make them undeniably real for all concerned, the initiators included. At the same time, in so far as all of the participants are to some degree made aware of the artificial or simulated character of these performances, the mundane reality of these episodes would seem to be belied. In such conditions, how are the participants led to appreciate these events as necessary enactments endowed with extra-ordinary meaning? We have seen that the novices' and the uninitiated's experience of these performances is such that, for both parties, deceiving others and being themselves deceived are inextricably combined. I have suggested that it is this interdependency of the novices' and the uninitiated's points of view, coupled with the incomplete perception of these episodes this interdependency implies, that sustains their commitment to the extra-ordinary import of these simulated episodes. However, for the initiators who knowingly orchestrate the novices' and the uninitiated's actions, the situation 
cannot be the same. Their "insider" point of view allows them to account for these actions entirely in terms of ordinary if somewhat obscure patterns of interpersonal behaviour, as instances of intimidation, mystification or simple deceit. For this reason, their own commitment to the exceptional nature of such enactments must come from elsewhere. The example of the Oyomo goat suggests that this commitment derives less from such public performances as it does from other prescribed actions, situated at a further remove from the novices' and the uninitiated's experience of the ritual. These actions are centred not around the simulated manipulation of persons (the novices and the uninitiated), but around the simulated manipulation of "objects" (that is, non-persons), notably those intervening in the execution, the preparation or the aftermath of such public episodes.

Such objects -- the Oyomo goat, the platform the novices dance upon prior to the "death of the so" (cf. Houseman 1993), or again, masks, particular liturgical formulae and so forth --, play a dual mediating role. While providing the material vehicles whereby representational and causal relations may be made to converge, they embed the initiators' simulations within auto-referential circuits incorporating other ceremonial events, notably those which enable the initiators to perform them. In short, these objects establish a circular relationship between the actions the initiators undertake and their ability to undertake them. The initiators, engaged in mandatory yet recognisably factitious performances which are unaccountable in any obvious sense, thus find themselves in a situation not unlike that of the novices and the uninitiated: they actively participate in events which are at once experientially grounded and conceptually uncertain. However, the basis for the initiators' attribution of extraordinary import to such object-centred simulations is not the same. It is by virtue of the recursive trajectories mediated by the objects they manipulate on such occasions, trajectories encompassing the initiators' own initiations, that these episodes may be held by them to embody a higher, indescribable order of significance, accessible solely by means of these equivocal acts themselves.

Here again, reflexivity may be said to play a generative, belief-sustaining role. The initiators' awareness of the simulated nature of Oyomo's silence, far from eroding their commitment to the significance of this episode, acts as a mainspring for the production of a shared yet largely indefinite meaning whereby this action may be held to be an essential, validating component of the young men's initiation.

In this way, questions regarding the actual or feigned nature of Oyomo's silent sacrifice, like those regarding the real or simulated character of the novices' secret execution, remain unresolved. In both cases, such issues are subordinated to the relational patterning that defines the highly specific context in which these actions take place. For the novices and the uninitiated women, this patterning concerns their interaction during the course of public or semi-public (avowedly secret) events; for the initiators, it pertains to the connection, mediated by special objets, between the "inside" operations they undertake far from the public eye and their own position as former novices.

It should be noted that in speaking of "initiators" in general, I have simplified things considerably. Certain initiators, having undertaken the ritual any number of times, are fully aware of all of the ceremonial procedures involved. By contrast, others, who participate as initiators for the first time, remain largely ignorant of many important details. In short, some of the initiated are more initiated than others. It seems reasonable to assume that the more knowledgeable the initiators become regarding the simulated actions they perform, the more the presumed meaningfulness of these actions draws on object-mediated circuits of the type described above. On the other hand, for those less familiar with the workings of such performances, this presumed meaningfulness is surely more closely linked to the supposition of some exclusive expertise the elders are held to have acquired, precisely by virtue of their 
long-term participation in the ritual. In other words, what are simulations for experienced initiators remain dissimulations for less experienced ones. Indeed, initiation, envisaged not as a one-time rite de passage but as an ongoing process of increasing ritual mastery, may be thought of as a progression from dissimulation to simulation, that is, from a commitment founded upon a complementary interaction within the framework of secrecy, to one founded upon an inscription of one's own actions within auto-referential circuits stretching over time.

\section{Conclusion}

By placing emphasis upon the generative properties of ceremonial simulations, I have argued that such performances intervene not so much to conceal the truth of singular events, or to supply the grounds for their metaphorical description, as to provide the reflexive conditions for the emergence of novel relational forms (Houseman and Severi 1998) underlying the participants' commitment to the ritual realities they enact.

The episodes I have briefly examined have been drawn from African male initiation rites. For the sake of the argument, I deliberately picked particularly violent, dramatic examples. However, simulated behaviours of the type illustrated by these episodes are fairly widespread. In most if not all (male) initiation rites, the novices are mysteriously killed, devoured or otherwise done away with in some manner or another. And many if not all such rites entail some sort of unusual sacrifice whereby the ritual's validity is ostensibly confirmed. For this reason, in the spirit of speculation, I wonder whether it might not be useful to envisage the recourse to illusory devices not only in initiation rites but in ritual generally as being organised around two different poles, which we might call "dissimulation" on the one hand, and "simulation" on the other.

In the case of "dissimulation", as illustrated by the novices' execution in the Gbaya Kara labi ritual, illusion is centred around the manipulation of persons. Various participants the novices and the uninitiated women -- are made to act in such a way that they are caught up in the co-ordinate patterning of each other's actions all the while being denied full access to the simulated performance they are involved in. The effectiveness of such dissimulations arises from the interdependency of the participants' respective perceptions, themselves deriving from differences in their modes of participation. On the other hand, what should rightly be called "simulation", as illustrated by the sacrifice of the Oyomo goat in the Beti so ritual, is founded upon the manipulation of non-persons: animals, objects, spells, images, etc. Its effectiveness arises from the mediating role such non-persons play in the substantiation of auto-referential trajectories in which relations of causality and representation converge.

I suspect that what I have called "dissimulation" may be a regular feature of many rituals, specifically those of the rite de passage variety - birth ceremonies, weddings, funerals and the like - in which new-born babies are ingenuously "discovered", conventionally despondent newly-weds are conveniently "captured", and professionally wailed corpses are "animated" in a range of ways. Such episodes invariably entail a degree of interactive staging in which for certain parties, by reason of their being either too close to the action or too far removed from it, the exact nature of the performance remains partially obscure. As for what I have called "simulation", this is also frequently encountered. I have mentioned the obvious case of divination, but sacrifice and other "offering", "blessing" or "therapeutic" rituals also often entail the simulative manipulation of special objects (or liturgical formulae) implying recursive circuits encompassing the officiant's ritually sanctioned aptitude to perform such acts.

It should be clear that I am not arguing for any sort of ritual typology : "dissimulation" and "simulation" may both be present in any given rite, as I have suggested for the case of 
initiation. This distinction is worth making, however, because of the different modes of reflexivity these two phenomena entail. In both cases, the participants are made partially aware of the illusory nature of the nonetheless mandatory performances they undertake. The conceptual uncertainty which results opens up a potential "space" in which a new, shared meaningfulness, relating to the extra-ordinary effectiveness of such performances, may emerge. The relational configurations that constrain the participants' experience of these events, while preventing the participants from forming a definite idea of these episodes (are they "real" or "fake"? what is their "true" meaning?, etc), act to structure and sustain their supposed significance. In other words, the participants' commitment to the actuality and the necessity of these performances stems directly from their own behaviour. Conceptual indeterminacy regarding the nature of these mysterious performances is subordinated to the well-defined pragmatic conditions of their execution. In both cases, these pragmatic conditions relate to the establishment of a necessary relationship between several divergent points of view. In the case of dissimulation, implying a spatial discontinuity, these points of view concern different persons interacting in different capacities simultaneously (e.g. novices, mothers). In the case of simulation, in which a temporal continuity is involved, they concern the same persons acting in different capacities at different moments (e.g. as initiators, as novices). In the first case, reflexivity takes the form of a mutual deception within the context of interactive complementarily, in the second, that of a recursive circularity mediated by the manipulation of material (or discursive) artefacts.

\section{References}

Bateson, G. 1979 Mind and Nature: A Necessary Unity. New York: Macmillan.

Boyer, $\mathrm{P}$.

1990 Tradition as Truth and Communication: A Cognitive Description of Traditional Discourse, Cambridge: Cambridge University Press.

Herdt, G.

1990 "Secret Societies and Secret Collectives", Oceania 60:360-381.

Houseman, M.

1984 "Les artifices de la logique initiatique" Journal des Africanists 54(1): 41-65.

1993 "The Interactive Basis of Ritual Effectiveness in a Male Initiation Rite", in P. Boyer (ed.) Cognitive Aspects of Religious Behaviour, Cambridge: Cambridge University Press.

2000 "La percezione sociale delle azioni rituali", Ethnosistemi $7: 67-74$ (special issue "Antopologia e psicologia").

Houseman, M. and C. Severi 1998 Naven or the Other Self. A Relational Approach to Ritual Action, Leiden: Brill Publications.

Laburthe-Tolra, $\mathrm{Ph}$.

1985 Initiations et sociétés secrètes au Cameroun. Essai sur la religion beti, Paris: Karthala.

La Fontaine, J. 1977 “The power of rites” Man (n.s.) 12: 421-37, 1977

Turner, V.

1967 The Forest of Symbols. Ithica: Cornell University Press.

1990 “Are There Universals of Performance in Myth, Ritual and Drama?”. In R. Schechner and W. Appel (eds.) By Means of Performance. Newcastle upon Tyne: Athenaeum Press. Vidal, $\mathrm{P}$.

1976 Garçons et filles. Le passage à l'âge d'homme chez les Gbaya Kara, Nanterre: Laboratoire d'éthnologie et de sociologie comparative. 